\title{
A novel M phase blocker, DCZ3301 enhances the sensitivity of bortezomib in resistant multiple myeloma through DNA damage and mitotic catastrophe
}

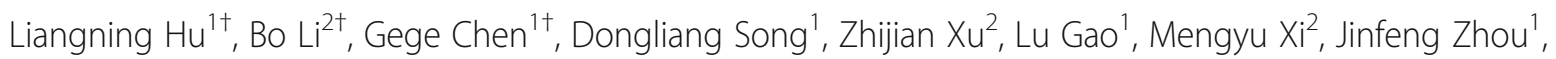
Liping Li ${ }^{1}$, Hui Zhang ${ }^{1}$, Qilin Feng ${ }^{1}$, Yingcong Wang ${ }^{1}$, Kang Lư ${ }^{1}$, Yumeng Lu', Wenxuan Bu ${ }^{1}$, Houcai Wang ${ }^{1}$, Xiaosong $\mathrm{Wu}^{1}$, Weiliang $\mathrm{Zhu}^{2^{*}}$ and Jumei Shi ${ }^{1,3^{*}}$

\begin{abstract}
Background: DCZ3301, a novel aryl-guanidino compound previously reported by our group, exerts cytotoxic effects against multiple myeloma (MM), diffused large B cell lymphoma (DLBCL), and T-cell leukemia/lymphoma. However, the underlying mechanism of its action remains unknown.

Methods: We generated bortezomib (BTZ)-resistant cell lines, treated them with various concentrations of DCZ3301 over varying periods, and studied its effect on colony formation, cell proliferation, apoptosis, cell cycle, DNA synthesis, and DNA damage response. We validated our results using in vitro and in vivo experimental models.

Results: DCZ3301 overcame bortezomib (BTZ) resistance through regulation of the $G_{2} / M$ checkpoint in multiple myeloma (MM) in vitro and in vivo. Furthermore, treatment of BTZ-resistant cells with DCZ3301 restored their drug sensitivity. DCZ3301 induced M phase cell cycle arrest in MM mainly via inhibiting DNA repair and enhancing DNA damage. Moreover, DCZ3301 promoted the phosphorylation of ATM, ATR, and their downstream proteins, and these responses were blocked by the ATM specific inhibitor KU55933.
\end{abstract}

Conclusions: Our study provides a proof-of-concept that warrants the clinical evaluation of DCZ3301 as a novel anti-tumor compound against BTZ resistance in MM.

Keywords: Multiple myeloma, Drug-resistance, DNA damage response, Cell cycle

\footnotetext{
* Correspondence: wlzhu@simm.ac.cn; shijumei@tongji.edu.cn

' Liangning Hu, Bo Li and Gege Chen contributed equally to this work.

${ }^{2}$ CAS Key Laboratory of Receptor Research, Drug Discovery and Design

Center, Shanghai Institute of Materia Medica, Chinese Academy of Sciences,

555 Zuchongzhi Road, Shanghai 201203, China

'Department of Hematology, Shanghai Tenth People's Hospital, Tongji University School of Medicine, 301 Yanchang Road, Shanghai 200072, China

Full list of author information is available at the end of the article
}

C C The Author(s). 2020 Open Access This article is licensed under a Creative Commons Attribution 4.0 International License, which permits use, sharing, adaptation, distribution and reproduction in any medium or format, as long as you give appropriate credit to the original author(s) and the source, provide a link to the Creative Commons licence, and indicate if changes were made. The images or other third party material in this article are included in the article's Creative Commons licence, unless indicated otherwise in a credit line to the material. If material is not included in the article's Creative Commons licence and your intended use is not permitted by statutory regulation or exceeds the permitted use, you will need to obtain permission directly from the copyright holder. To view a copy of this licence, visit http://creativecommons.org/licenses/by/4.0/ The Creative Commons Public Domain Dedication waiver (http://creativecommons.org/publicdomain/zero/1.0/) applies to the data made available in this article, unless otherwise stated in a credit line to the data. 


\section{Introduction}

Multiple Myeloma (MM) is a malignant hematologic disease characterized by clonal proliferation of malignant plasma cells. In 2003, the Food and Drug Administration (FDA) approved bortezomib (BTZ) as a first-line drug for MM therapy [1, 2]. However, over the past decade, there has been an increase in the cases of drugresistance and MM relapse following BTZ treatment [3]. Once a patient develops resistance, BTZ is rendered ineffective at the usual tolerable doses [4]. Since the safety margin of BTZ is very narrow, increasing its dose will significantly augment the risk of side effects. Thus, there is an urgent need to develop new therapeutic compounds to counter BTZ resistance in MM.

Chromosomal aberrations are one of the causative factors for cell chemoresistance. Chromosomal aberrations can lead to the inactivation of essential 'housekeeping genes' that are involved in the regulation of several important cellular functions, including gene transcription, DNA synthesis, DNA repair, cell cycle arrest, senescence, and apoptosis [5]. Therefore, targeting these mechanisms may improve the outcomes of drug resistance. Drug resistant cells always exhibit a robust activation of the DNA damage response (DDR) and a higher intrinsic DNA repair activity [6, 7]. Therefore, these cells can withstand the effects of DNA damaging drugs and can repopulate cancer tissues with therapy-resistant cells after treatment [8].

For decades, genotoxic drugs have been a mainstay in cancer therapy. These drugs may play a role in the inhibition of cell proliferation at all stages of the cell cycle [9]. There are two critical pathways that participate in the regulation of responses after DNA damage: one is the ataxia telangiectasia mutated (ATM)-checkpoint kinase 2 (CHK2)-P53 pathway. This pathway is mainly related to the $G_{1} / S$ phase transition [10]. The other is the ATM- and Rad3-related (ATR)-checkpoint kinase 1 (CHK1)-Cdc25 pathway. When DNA damage occurs, it plays a critical role during the intra-S phase or $G_{2} / M$ phase [11]. However, increasing evidence indicates that the ATM/CHK2 and ATR/CHK1 pathways may interact in response to DNA damage [12].

DCZ3301 is a novel aryl-guanidino compound synthesized by our group. We have previously reported that it exhibits strong anti-cancer activity in $\mathrm{MM}^{13}$, diffuse large B-cell lymphoma (DLBCL) [13] and T-cell leukemia/lymphoma [14]. Results from our studies have so far indicated that DCZ3301 possesses a strong ability to block cancer cells in the $G_{2} / M$ phase. Furthermore, it may affect several other cancer-associated pathways regulated by STAT3, NFкB, AKT, and ERK1/2. Moreover, DCZ3301 retains its anti-MM activity in the presence of exogenous cytokines (IL-6 or VEGF) or BMSCs [15]. Thus, we speculated that DCZ3301 may counter drug resistance in MM. However, the underlying mechanism of DCZ3301-mediated $G_{2} / M$ phase arrest in $M M$ or DLBCL remains unknown. Besides, it is not known whether DCZ3301 blocks the tumor cells in the $G_{2}$ or $M$ phase. In this study, we tested the inhibitory effects of DCZ3301 on BTZ-resistant MM cells in vitro and in vivo, and tried to elucidate the underlying mechanism of DCZ3301-mediated $G_{2} / M$ phase arrest. Our results showed that DCZ3301 treatment activated the ATMATR-CHK1 signaling pathway and restored the sensitivity of BTZ-resistant cells.

\section{Materials and methods Reagents}

DCZ3301 was kindly provided by Weiliang Zhu (Shanghai Institute of Materia Medica, Chinese Academy of Sciences, Shanghai, China) and the molecular structure is as shown in Fig. 1a with molecular weight of 464.0. DCZ3301 was stored at $-20^{\circ} \mathrm{C}$ in DMSO (Sigma, St. Louis, MO) and the concentration of stock solution was $40 \mathrm{mM}$. Panobinostat was purchased from Selleck Chemicals (Houston, TX, USA). BTZ was obtained from Sigma (St. Louis, MO, USA). ATM kinase inhibitor KU55933 was obtained from Targetmol (Boston, MA, USA).

\section{Cell lines and culture condition}

NCI-H929 and HEK-293 T were bought from American Type Culture Collection (ATCC) (Manassas, VA, USA). The BTZ-resistant MM cell line RPMI-8226R5 and the BTZ-sensitive cell line RPMI-8226 were kindly provided by Fenghuang Zhan (Department of Internal Medicine, University of Iowa, Iowa City, IA, USA). The BTZresistant cell line NCI-H929R was obtained by increasing extracellular concentrations of BTZ over a period of 10 months step by step (Fig. 1b). The BTZ-sensitive cell lines were routinely cultured in RPMI-1640 medium containing $10 \%$ fetal bovine serum (FBS), $100 \mathrm{IU} / \mathrm{mL}$ penicillin and $100 \mu \mathrm{g} / \mathrm{mL}$ streptomycin (GIBCO, Grand Island, NY), 5\% Carbon dioxide. The BTZ-resistant cell lines were cultured in the presence of $20 \mathrm{nM} \mathrm{BTZ}$ in order to maintain the characteristics of BTZ resistance. And the BTZ was stopped adding for at least two weeks before every experiment. HEK-293 T cell line was cultured in DMEM/HIGH GLUCOSE medium (Gibco, Carlsbad, CA, USA). Cell lines were certificated by Short Tandem Repeat profiling (Shanghai Biotechnology Co., Ltd., Shanghai, China).

We used Ficoll-Hypaque density gradient centrifugation in order to gain the primary human cell lines. Primary $\mathrm{CD}_{138^{+}} \mathrm{MM}$ cells were selected from the bone marrow mononuclear cells (BMMCs) derived from MM patients. We stained these cells using human APC conjugated anti-CD $138^{+}$antibody (BioLegend, Sandiego, 


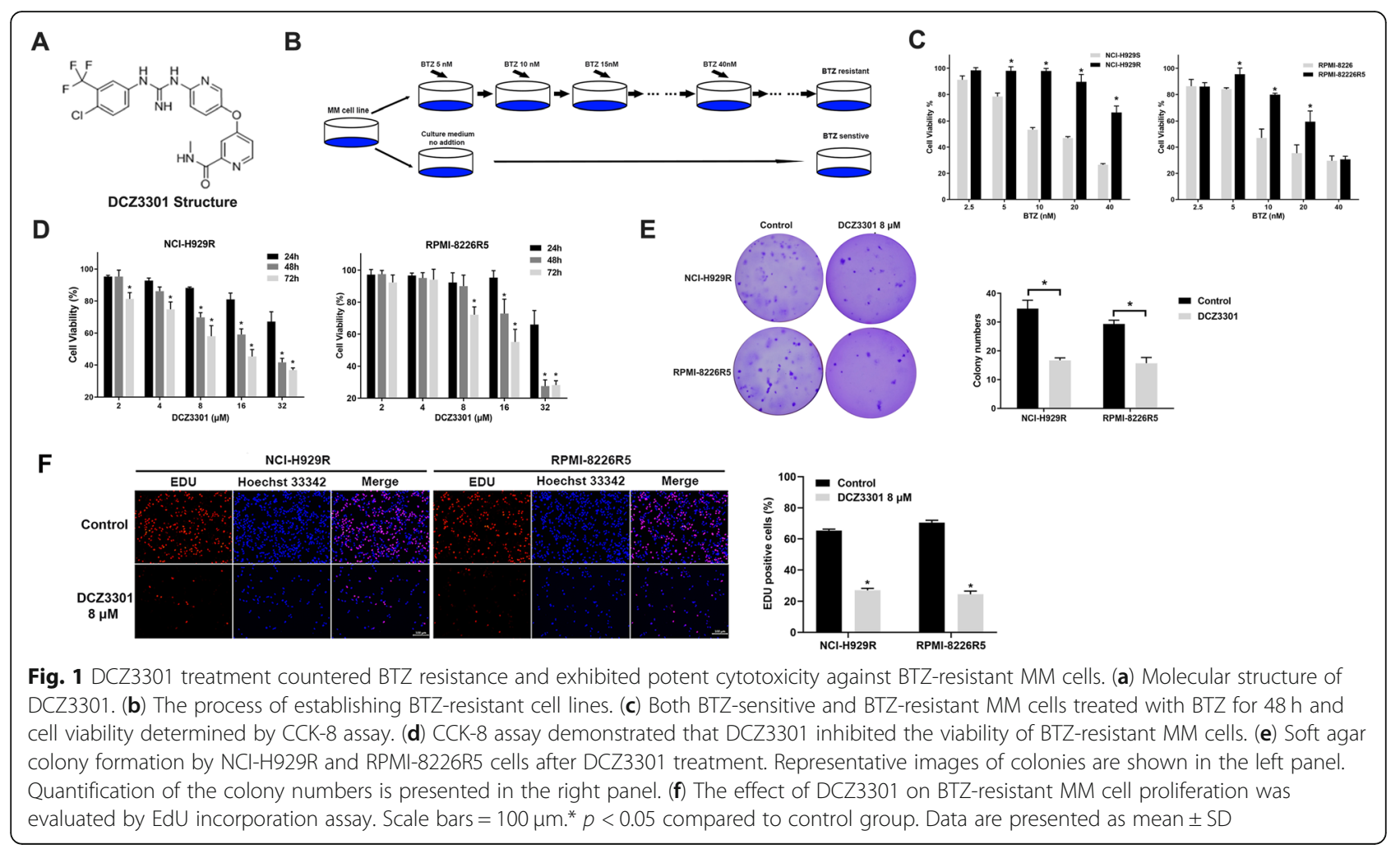

CA, USA). Blood samples were collected from healthy volunteers and Ficoll-Hypaque density gradient centrifugation was used to obtain peripheral blood mononuclear cells (PBMCs). In compliance with Declaration of Helsinki, written informed consent was obtained from MM patients and healthy donors. This study was approved by the institutional review board of the Shanghai Tenth People's Hospital, Tongji University.

\section{Cell viability and apoptosis assay}

Cells were seeded in 96-well plates at a density of $2 \times$ $10^{5}$ cells/ml. After 24, 48 or $72 \mathrm{~h}$ treatment of DCZ3301, cell viability was assessed by using CCK8 kit (Yeasen Biotech, Shanghai, China). The half maximal inhibition concentration $\left(\mathrm{IC}_{50}\right)$ was determined by using the CalcuSyn software program (CalcuSyn; Biosoft, USA). Alternatively, cells were treated with DCZ3301, BTZ and/or ZVAD-FMK ( $50 \mu \mathrm{M}$, Selleckchem, Houston, TX) and then cell apoptosis was assessed by flow cytometry with Annexin V-FITC and PI (BD Pharmingen, San Diego, $\mathrm{CA})$. The percentage of apoptosis in $\mathrm{CD} 138^{+}$primary MM cells was evaluated by staining Annexin-V and 7aminoactinomaycin D (7-AAD, KeyGen Biotech, China). All percentage of cell apoptosis was measured by flow cytometer FACS Canto II flow cytometer (BD Bioscience, California, USA).

\section{Soft agar assay of colony formation}

2000 cells mixed with RPMI1640 media containing 20\% FBS and $0.33 \%$ agar were layered on top of the base layer of $0.5 \%$ agar. And we seeded these cells in 12 -well plates. Then we use digital camera to take pictures of the colony. Image J 1.51j8 software (Wayne Rasband National Institutes of Health, Washington, USA) was used to scan and count the overall numbers of colony in the pictures.

\section{Cell cycle analysis}

After treatment of DCZ3301, we collected the MM cells and resuspended the cells in $200 \mu \mathrm{l}$ PBS. Cold $70 \%$ ethanol was used to fix cells morphology and then cells were washed in PBS. At last cells were dyed using $500 \mu \mathrm{l}$ of PI/RNase staining buffer (BD, Pharmingen, Franklin Lakes, NJ, USA). In order to detect the percentage of $M$ phase arrest cells, the cells were stained in $100 \mu \mathrm{L}$ cell staining buffer with $3 \mu \mathrm{L}$ Alexa Fluor ${ }^{\circ} 488$-conjugated anti-phospho (Ser10)-Histone H3 polyclonal antibody (BioLend Inc., San Diego, CA, USA) for $30 \mathrm{~min}$ at room temperature according to the instruction. After staining, cells were detected using flow cytometry FACS Canto II flow cytometer (BD Bioscience, California, USA).

\section{Neutral comet assay}

Comet assays were conducted following protocols provided by Comet Assay ${ }^{\odot}$ Kit (Trevigen, Gaithersburg, 
USA). After treated with DCZ3301, cells were collected. $1 \times 10^{5}$ cells $/ \mathrm{ml}$ cells were combined with LMA agarose. Cell lysis was neutralized in neutral electrophoresis buffer for $30 \mathrm{~min}$ and then run for $45 \mathrm{~min}$ at $21 \mathrm{~V}$. Cells then were sunk with DNA precipitation buffer and washed using $70 \%$ ethanol. Slides were dried at $37^{\circ} \mathrm{C}$ before staining with SYBER green. Finally, the length of comet was observed using fluorescence microscopy (Leica, Wetzlar, Germany). CaspLab Comet Assay Software (CaspLab, Wroclaw, Poland) was used to evaluate the comet length of the relative cells.

\section{Immunofluorescence assay}

$2 \times 10^{5}$ cells $/ \mathrm{ml}$ cells were seeded in 6 -well plates, and then administrated with DCZ3301 for $48 \mathrm{~h}$. Then cells were harvested and fixed in 4\% paraformaldehyde for 30 min. After washed in PBS, 3\% BSA was used to block cells. And then permeated with $0.1 \%$ TritonX-100, and incubated $\gamma$-H2A.X (1:250 dilution; Abcam, Cambridge, MA, USA) or $\alpha$-tublin (1:500 dilution; Sigma-Aldrich, St. Louis, USA) at $37^{\circ} \mathrm{C}$ for $1 \mathrm{~h}$. The secondary antibody Dylight $^{\mathrm{mm}}$ 488-conjugated Affinipure Donkey antibody (1: 400 dilution; Jackson Immuno Research Laboratory, USA) was incubated with cells at room temperature for $2 \mathrm{~h}$, followed by incubation with 4,6-diamidino-2-phenylindole (DAPI) (Sigma-Aldrich, St. Louis, MO, USA) for $10 \mathrm{~min}$ at room temperature. A confocal laser scanning microscope and Zen2011 software was used to analyze the fluorescence.

\section{EdU incorporation assay}

The incorporation of 5-ethynyl-2'-deoxyuridine (EdU) was measured using an EdU kit (RiboBio, Guangzhou, China) following the manufacturer's protocol. Briefly, cells were exposed to DCZ3301 for $48 \mathrm{~h}$ and harvested. $2 \mathrm{~h}$ before collection, cells were treated with $50 \mu \mathrm{M}$ EdU at $37^{\circ} \mathrm{C}$. Then cells were harvested and resuspended with PBS, followed by permeabilization with TritonX100 (Sigma-Aldrich, St. Louis, MO, USA). Azideconjugated Alexa Fluor 567 dye and Hoechst 33342 were used to dye the cells. At last we observed the DCZ3301induced proliferation inhibition using fluorescence microscopy.

\section{Western blot analysis}

Briefly, cells were collected and resuspended at $4{ }^{\circ} \mathrm{C}$. Then we fractionated the proteins in $10 \%$ or $12.5 \%$ SDSPAGE and transferred to nitrocellulose membrane. 5\% skim milk was used to block the membranes at room temperature for $1 \mathrm{~h}$. After that, those membranes were incubated with primary antibodies overnight at $4{ }^{\circ} \mathrm{C}$. Fluorescence-conjugated secondary antibodies were added to incubated with membranes the other day. The expression was measured by Odyssey infrared imaging system (LI-COR Biosciences, Lincoln, USA). The $\beta$-actin was used to normalize the amount of protein in each sample.

The primary antibodies cleaved caspase 3 (\#9661, 1: $1000)$, cleaved caspase 8 (\#9496, 1:1000), cleaved caspase 9 (\#9532S, 1:1000), Bax (\#2772, 1:1000), Bcl-2 (\#2872, 1: 1000), Cdc25C (\#4688, 1:1000), phospho-Cdc25C (\#32051, 1:1000), Histone H3 (\#4499,1:1000), phosphoHistone H3 (\#3377S, 1:1000), $\beta$-actin (\#3700, 1:1000), Rad51 (\#8875, 1:1000) were from Cell Signaling Technology (CST, Beverly, MA,USA). Cyclin B1 (\#ab32052,1: 1000), CDK1 (\#ab32384,1:1000), $\gamma$ H2A.X (\#ab2893, 1: 1000), Histone H2A.X (\#ab124781,1:1000), phosphoATM (\#ab81292, 1:1000), ATM (\#ab32420,1:1000), phospho-ATR (\#ab178407, 1:1000), phospho-CHK1 (\#ab47318,1:1000), CHK1 (\#ab40866, 1:1000), phosphoCHK2 (\#ab85742, 1:1000), CHK2 (\#ab47433, 1:1000), phospho-DNA PKCs (\#ab124918, 1:1000) were from Abcam (Abcam, Cambridge, UK). BRCA1 (\#sc135732, 1: 200), BRCA2 (\#sc293185, 1:200) were from Santa Cruz (Santa Cruz, California, USA).

\section{NHEJ and HR reporter assay}

NHEJ and HR reporter assays were carried out according to a previously published report $[16,17]$. Briefly, we use HEK-293 T cell line as the standard model cell line for this experiment. Lipofectamine 2000 transfection agent (Invitrogen, MA, USA) was used to transfect a mutant GFP plasmid containing a specific Isce-I site (DR-GFP) and an Isec-I-expressing plasmid (Isce-I) or NHEJ plasmid to HEK-293 T cells according to the instructions. After $5 \mathrm{~h}$, the old culture medium was removed and new culture medium containing $8 \mu \mathrm{M}$ DCZ3301 was added. After $24 \mathrm{~h}$, the percentage of GFP positive cells (GFP\%) was assessed using a FACS Canto II flow cytometer (BD Bioscience, California, USA) and the HR or NHEJ percentages were calculated using the formula:

(Percentages of HR or NHEJ $)=($ GFP\% of HR infected or NHEJ transfected cells $)$ $\div($ GFP $\%$ of corresponding GFP Vector transfected cells)

\section{In vivo animal experiments}

BALB/C nude mice were bought from the Shanghai Laboratory Animal Center (SLAC, Shanghai, China). Resuspend NCI-H929R cells with serum-free culture medium, mix the cell resuspension with the Matrigel (Corning, NY, USA) in proportion to 1:1 according to the instruction. Subcutaneously inject $100 \mu \mathrm{L}$ mixture into the upper flank of nude mice rapidly. The density of cells in the mixture is about $4 \times 10^{8}$ cells $/ \mathrm{mL}$. When the tumors were visible, mice were randomly divided into control group (vehicle, daily), BTZ group (1 day of 0.5 
$\mathrm{mg} / \mathrm{kg}$ BTZ followed by 2 days of vehicle), DCZ3301 group ( 1 day of vehicle followed by 2 days of $50 \mathrm{mg} / \mathrm{kg}$ DCZ3301) and combination group (1 day of $0.5 \mathrm{mg} / \mathrm{kg}$ BTZ followed by 2 days of $50 \mathrm{mg} / \mathrm{kg}$ DCZ3301, cyclical repetition). Mice were injected for 20 days. The tumor volume was calculated every two days and calculated as $4 \times 3.14 / 3 \times(\text { width } / 2)^{2} \times($ length $/ 2)$. Mice were sacrificed by cervical dislocation. Tumor specimens were fixed with $4 \%$ paraformaldehyde. We also performed hematoxylin and eosin (H\&E), Ki-67, cleaved-caspase 3, TUNEL, $\gamma$-H2A.X, and phospho-CHK1 staining. The relative protein expressions were assessed by Image-pro plus. Version 6.0.0.260 (Media Cybernetics Inc., Maryland, USA).

In order to test the acute toxicity of DCZ3301 in vivo, we injected vehicle or $50 \mathrm{mg} / \mathrm{kg}$ DCZ3301 into healthy BALB/C nude mice intraperitoneally for 2 weeks. Then we analyzed the level of glutamic-pyruvic transaminase (ALT), glutamic-oxalacetic transaminase (AST), creatinine $(\mathrm{Cr})$, and urea nitrogen $(\mathrm{BUN})$ in serum. Alanine aminotransferase and aspartate aminotransferase assay kit (Nanjing Jiancheng Bioengineering Institute, China) were used for determining the level of ALT, AST, Cr and BUN. In this study, all animal-related experimental operations were licensed by the Animal Care and Use Committee of Shanghai Tenth People's Hospital, Tongji University.

\section{Statistics}

We performed all experiments in triplicate. The statistical significance was measured using the Student's t-test or one-way variant analysis (ANOVA) with SPSS 20.0 (SPSS Inc., Chicago, IL, USA). Results with $p<0.05$ were identified to be significant. Combination Index $(\mathrm{CI})$ was used to evaluate synergistic and antagonistic interactions. And we use CalcuSyn software program (CalcuSyn; Biosoft, USA) to calculated the relative CI value.

\section{Results \\ DCZ3301 treatment countered BTZ resistance and exhibited potent cytotoxicity against resistant MM cells}

DCZ3301 is a novel aryl-guanidino compound whose molecular structure is shown in Fig. 1a. The BTZresistant MM cell lines NCI-H929R and RPMI-8226R5 were used in this study. The process of cell line establishment is presented in Fig. 1b. The established cell lines were treated with BTZ to confirm their resistance to the drug. Both cell lines were highly resistant to BTZ (NCI-H929R IC IC $_{50}: 48.7 \pm 3.2 \mathrm{nM}$, RPMI-8226R5 IC 50 : $34.6 \pm 2.3 \mathrm{nM}$ ) (Fig. 1c) after $48 \mathrm{~h} \mathrm{BTZ}$ treatment compared to the BTZ-sensitive cell lines (NCI-H929S $\mathrm{IC}_{50}$ : $\left.15.6 \pm 1.2 \mathrm{nM}, \mathrm{RPMI}-8226 \mathrm{IC}_{50}: 9.8 \pm 1.1 \mathrm{nM}\right)$. These results confirmed the BTZ resistance of the established cell lines. Next, we carried out the CCK8 assay and the soft agar clonogenic assay to investigate the antiproliferative activity of DCZ3301 on BTZ-resistant MM cells. BTZ-resistant cell lines were treated with varying concentrations of DCZ3301 $(2-32 \mu \mathrm{M})$ for 24,48 and $72 \mathrm{~h}$. DCZ3301 treatment decreased the cell viability in a time- and dose-dependent manner (Fig. 1d). Moreover, DCZ3301 treatment significantly inhibited the colony formation by both cell lines, indicating that DCZ3301 inhibited BTZ-resistant MM cell proliferation (Fig. 1e). EdU incorporation was significantly suppressed in DCZ3301 treated BTZ-resistant MM cells (Fig. 1f). These results demonstrated that DCZ3301 markedly affected the proliferation of BTZ-resistant MM cells.

\section{DCZ3301 induced apoptosis in BTZ-resistant MM cells and} relapsed/refractory primary $\mathrm{MM}$ cells

We performed flow cytometry and western blot to examine whether the anti-proliferative activity exhibited by DCZ3301 involved apoptosis induction in treated cells. Treatment of NCI-H929R cells with various concentrations $(4 \mu \mathrm{M}, 8 \mu \mathrm{M}, 16 \mu \mathrm{M})$ of DCZ3301 for $48 \mathrm{~h}$ led to a significant increase in the number of early-stage (Annexin- $\left.\mathrm{V}^{+} / \mathrm{PI}^{-}\right)$and the late-stage $\left(\right.$Annexin $-\mathrm{V}^{+} / \mathrm{PI}^{+}$) apoptotic cells compared to the DMSO-treated control cells (Fig. 2a). Furthermore, the pro-apoptotic effect induced by $16 \mu \mathrm{M}$ DCZ3301 treated for $24 \mathrm{~h}, 48 \mathrm{~h}$ and $72 \mathrm{~h}$ increased in a time-dependent manner (Fig. 2b). We could inhibit the pro-apoptotic effect by Z-VAD-FMK, a pan-caspase inhibitor (Fig. 2c). Further, we performed western blot to evaluate the effects of DCZ3301 on the expression of caspase enzymes, and the anti-apoptotic Bcl-2 and pro-apoptotic Bax proteins. Our results showed that $48 \mathrm{~h}$ treatment of BTZ-resistant MM cells with DCZ3301 enhanced the cleavage of caspase-3, 8, and 9 and poly (ADP)-ribose polymerase (PARP) in a dose-dependent manner. Furthermore, DCZ3301 treatment decreased and increased the expression of Bcl-2 and Bax, respectively (Fig. 2d). To validate these results in patient-derived cells, $\left(\mathrm{CD} 138^{+}\right)$BTZ-resistant $\mathrm{MM}$ cells from three refractory/relapsed MM patients were treated with DC3301. DCZ3301 significantly induced apoptosis in the primary MM cells (Fig. 2e). In contrast, DCZ3301 treatment at concentrations as high as $30 \mu \mathrm{M}$ failed to induce significant cytotoxicity in PBMCs from three healthy volunteers (Fig. 2f).

\section{DCZ3301 induced M phase arrest in BTZ-resistant MM cells}

In addition to apoptosis induction, the inhibition of the cell cycle progression may be an important efficacy parameter of anti-cancer drugs. Therefore, we evaluated the effects of DCZ3301 on cell cycle progression. DCZ3301 treatment induced a significant accumulation of cells in $\mathrm{G}_{2} / \mathrm{M}$ in a dose- and time-dependent manner (Fig. 3a). 


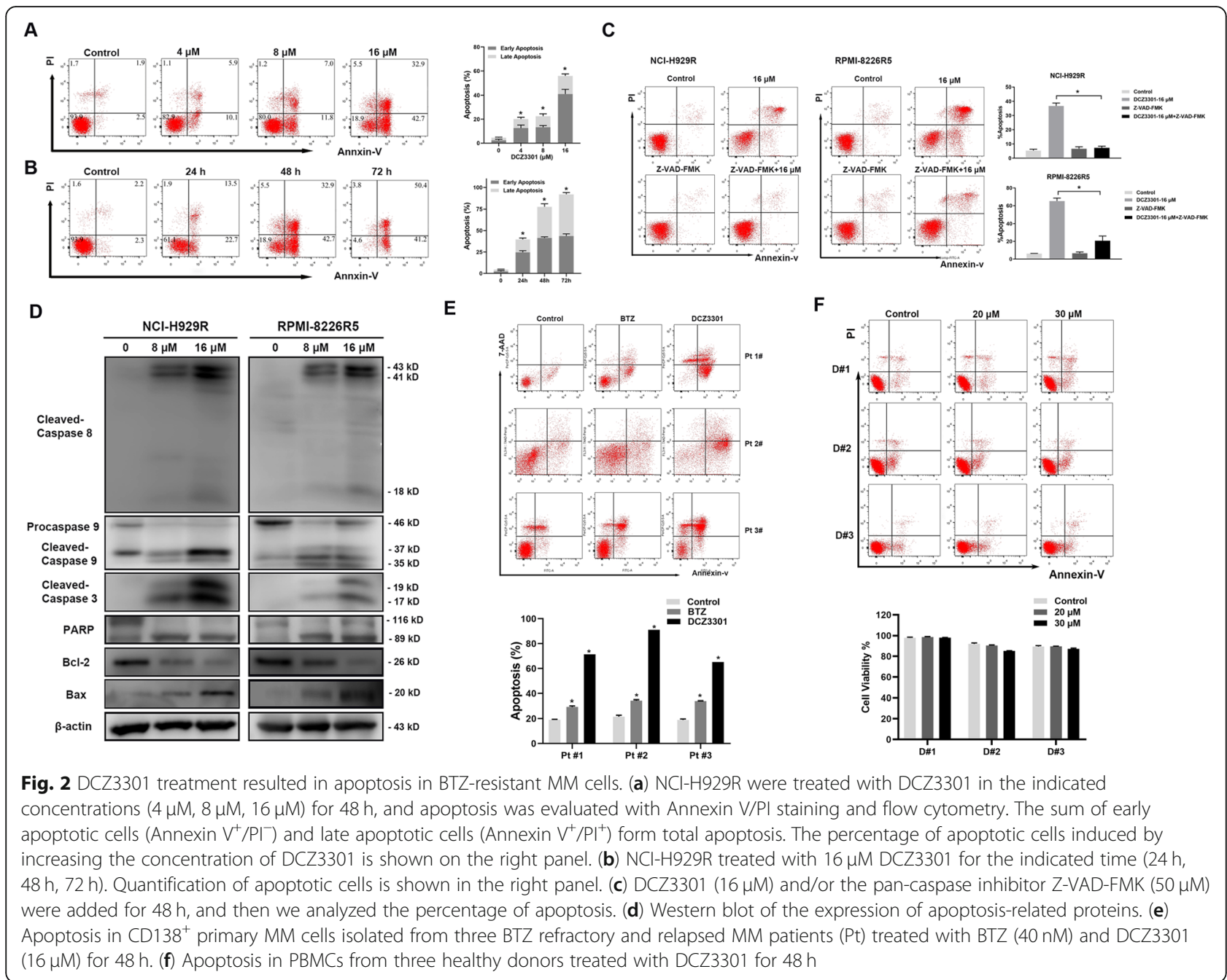

To further elucidate the mechanisms underlying DCZ3301 induction of $G_{2} / M$ phase arrest, we analyzed the DCZ3301-mediated cell cycle arrest of BTZ-resistant cells using an anti-phosphorylated Histone $\mathrm{H} 3$ antibody. Phosphorylation at Ser10 of Histone H3 is strongly correlated with chromosome condensation during mitosis, and the $M$ phase can be identified using the antiphosphorylated Histone $\mathrm{H} 3$ antibody [18]. Interestingly, results from both flow cytometry and western blot analyses confirmed that treatment with DCZ3301 upregulated the level of phosphorylated Histone H3 (Fig. 3b-c), indicating that DCZ3301 treatment specifically increased the $M$ phase cell cycle arrest without influencing the number of the $G_{2}$ phase cells. Simultaneously, the expression of several $G_{2} / M$ phase proteins was modulated by DCZ3301 (Fig. 3c). DCZ3301 reduced cyclin B1, CDK1, and $\mathrm{Cdc} 25 \mathrm{C}$ expression and upregulated the levels of phosphorylated Cdc25C.

\section{DCZ3301 enhanced the DNA damage response and} impaired DNA repair in BTZ-resistant cells

The $M$ phase arrest is often related to DNA damage, and DCZ3301 specifically induced the M phase arrest in BTZresistant MM cells. We treated NCI-H929R and RPMI8226R5 cells with DCZ3301 for $48 \mathrm{~h}$ and subsequently performed the comet assay to measure the double-strand breaks (DSBs) in DNA. The characteristic comet tails were observed in DCZ3301-treated cells, suggesting that the compound enhanced DNA damage in BTZ-resistant cells (Fig. 4a). The level of $\gamma$-H2A.X has been used as a marker to detect and quantify the early phase of DSBs [19]. In this study, we used immunofluorescence (IF) analysis to evaluate the $\gamma$-H2A.X levels, and our results revealed a higher $\gamma$-H2A.X expression in DCZ3301 treated cells than baseline $\gamma$-H2A.X levels (Fig. 4b). These results were supported by parallel DCZ3301-mediated upregulation of $\gamma$ H2A.X, phospho-ATM, and phospho-ATR, the key proteins involved in DNA DSBs (Fig. 4c). Moreover, we 


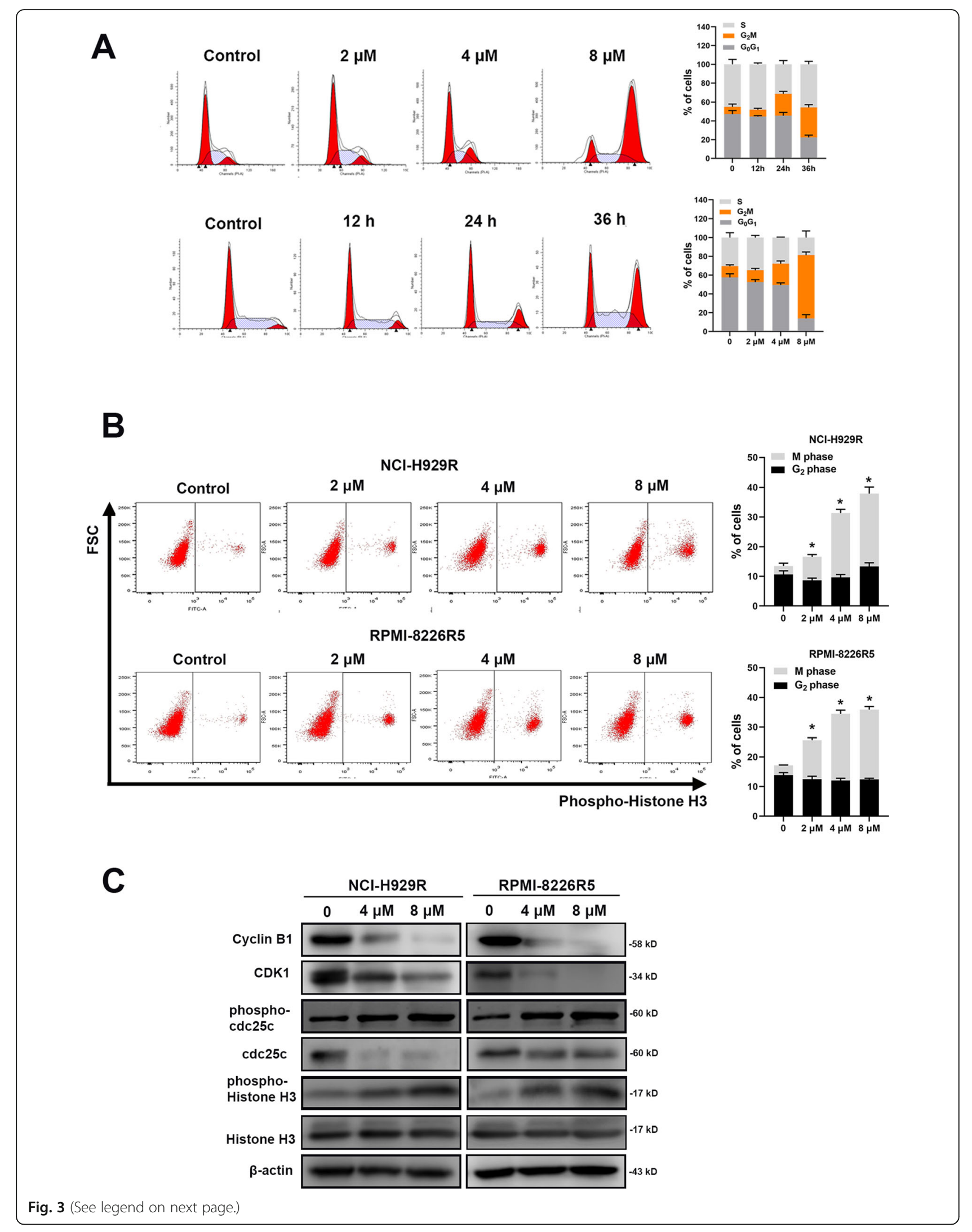


(See figure on previous page.)

Fig. 3 DCZ3301 caused M phase arrest in BTZ-resistant cells. (a) NCI-H929R treated with DCZ3301 with indicated concentrations (the upper panel) and for the indicated time (lower panel) and cell cycle arrest analyzed using PI staining and flow cytometry. (b) The percentage of M phase arrest induced by DCZ3301 was tested by staining with Alexa Fluor ${ }^{\oplus} 88$-conjugated anti-phospho (Ser10)-Histone $\mathrm{H} 3$ polyclonal antibody and flow cytometry. Quantification of M phase cell arrest induced by DCZ3301 is shown on the right panel. Data represent the mean of three independent experiments. ${ }^{*} p<0.05$ (c) Western blot showing the expression of $\mathrm{G}_{2} / \mathrm{M}$ phase-related proteins in BTZ-resistant MM cells treated with DCZ3301

checked the expression of downstream proteins, and found that the phosphorylation of CHK1 were activated (Fig. 4c). However, the level of phosphorylated CHK2 was not affected. Based on the fact that DCZ3301 was an anticancer agent that induced DNA damage and the $M$ phase cell cycle arrest, we speculated that DCZ3301 might also activate the ATM-ATR/CHK1 signaling pathway. Towards this, both NCI-H929R and RPMI-8226R5 cells were treated with DCZ3301 and subsequently exposed to KU55933, an ATM inhibitor. Our western blot results revealed that KU55933 could reverse the DCZ3301mediated upregulation of phospho-CHK1 and phospho-

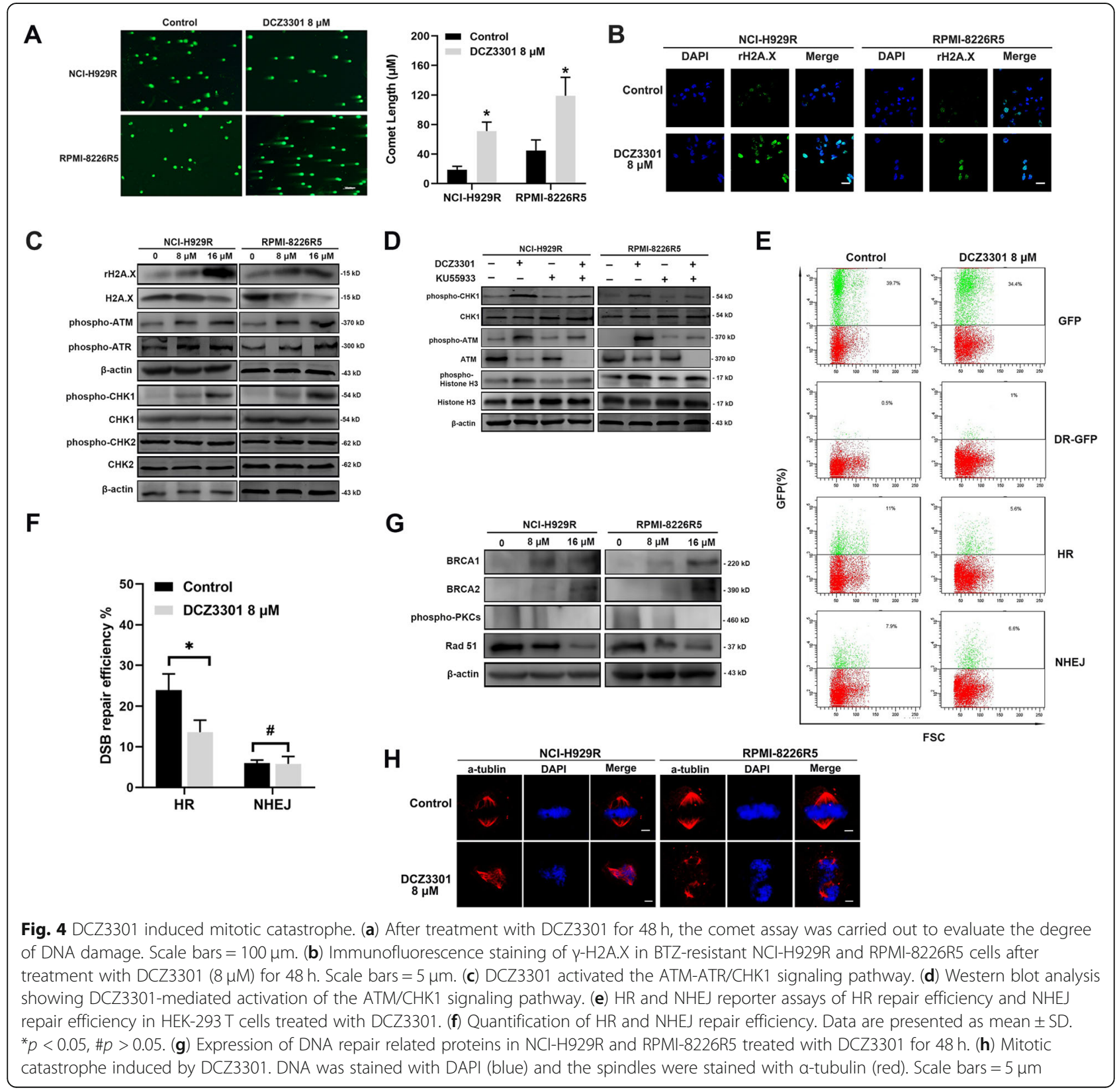


ATM (Fig. 4d). Furthermore, KU55933 treatment modulated the phosphorylation of Histone H3, indicating that the $\mathrm{M}$ phase cell cycle arrest could be attributed to the activation of the ATM/CHK1 signaling pathway.

A DNA damage response for the efficient and appropriate repair of DSBs is essential for the preservation of genomic integrity [19]. However, the repair of genotoxic agentinduced DSBs by the non-homologous end joining (NHEJ) or HR repair pathways promotes resistance and subsequent relapse in patients [20]. Thus, we used GFP-based repair assays to evaluate whether DCZ3301 could impair the DNA repair pathways. Our results showed that DCZ3301 suppressed HR but had little effect on NHEJ (Fig. 4e and f). Moreover, western blot showed that DCZ3301 could activate BRCA1/2 and decrease the expression of phosphoDNA PKCs and RAD51, the key regulators of DNA repair (Fig. 4g). DNA damage and aberrant DNA repair usually turn cells into aneuploids, which may lead to mitotic catastrophe [21]. Our results showed that following treatment with DCZ3301, both NCI-H929R and RPMI-8226R5 cells exhibited multipolar mitotic spindles (Fig. 4h).

\section{DCZ3301 exhibited synergistically with BTZ in vitro}

Since DCZ3301 had a cytotoxic effect on BTZ-resistant MM cells, we questioned whether DCZ3301 treatment could re-sensitize BTZ-resistant MM cells. To answer this, we added both DCZ3301 and BTZ simultaneously to the MM cell culture and calculated the combination Index (CI) between DCZ3301 and BTZ. The CI is considered the gold standard to define the synergism of drug-drug interactions $[22,23]$. CI values $=1$ always represents an additive effect, while $\mathrm{CI}$ values $<1$ and $>1$ indicate synergistic and antagonistic interactions, respectively. Thus, a low CI value stands for strong synergism and vice versa. According to our previous study, DCZ3301 showed synergism with BTZ in MM.1S (BTZsensitive $M M$ cells) [15]. In the current study, we observed similar results in the BTZ-sensitive MM cells, NCI-H929S, and RPMI-8226 (Fig. 5a and b). Interestingly, DCZ3301 showed a higher synergistic effect with BTZ in the BTZ-resistant cell lines NCI-H929R and RPMI-8226R5 than in BTZ-sensitive MM cells (Fig. 5c and $\mathrm{d}$ ). The detailed concentrations of DCZ3301 and BTZ are presented in Supplementary Table 1-8. Furthermore, DCZ3301 was synergistic with the histone deacetylase (HDAC) inhibitor panobinostat in NCIH929R and RPMI-8226R5 cells (Supplementary Figure 1) over a broad range of concentrations, and the synergy increased with higher panobinostat doses. To understand the underlying mechanism behind the efficacy of combination treatment, cell cycle analysis was carried out for BTZ-resistant cells via flow cytometry. More BTZ-resistant cells were observed in $G_{2} / M$ phase arrest when treated with combination therapy than when treated with a single compound (Fig. 5e and f). In addition, the expression of cyclin $\mathrm{B} 1$ and $\mathrm{CDK} 1$ was further decreased, whereas the expression of the apoptosis marker Bax was higher in cells subjected to combination treatment (Fig. 5g).

\section{Synergistic effect of DCZ3301 and BTZ against BTZ- resistant $\mathrm{MM}$ in vivo}

We validated these in vitro findings in in vivo experiments. Combinational treatment induced greater tumor inhibition than treatment with BTZ or DCZ3301 alone (Fig. 6a and b), indicating that the treatment of BTZresistant cells with DCZ3301 could restore the sensitivity to BTZ in vivo. The body weight of the mice was monitored during the treatment to evaluate potential side effects, and 20-day treatment with DCZ3301 did not cause any changes in the animal weight (Fig. 6c). Besides, no significant differences in the serum levels of ALT, AST, $\mathrm{Cr}$, or BUN were observed in mice treated with DCZ3301 (50 mg/kg) (Fig. 6d and e), indicating that it was well tolerated. H\&E staining showed that cell shrinkage and fragmentation increased upon DCZ3301 and combinational treatment (Fig. 6f). Further, we carried out the TUNEL staining to detect apoptosis and immunohistochemical staining (IHC) to measure the expressions of $\mathrm{Ki}-67, \gamma$-H2A.X, cleaved-caspase 3, phospho-ATM and phospho-CHK1 (Fig. 6f). And the percentages of cell shrinkage and TUNEL-positive cells were quantified with image-Pro plus. Both the percentage of cell shrinkage and TUNEL-positive cells were increased in DCZ3301 and combination treatment groups (Fig. 6g). The results of quantified relative protein expressions in Fig. 6h showed that Ki-67 expression was downregulated, whereas the cleavage caspase- 3 were upregulated by both DCZ3301 alone and combinational treatment. Moreover, consistent with our in vitro results, the expression of $\gamma$-H2A.X, phospho-ATM, and phospho-CHK1 were upregulated in vivo. Collectively, the data of the present study suggest that DCZ3301 is a promising compound to counter BTZ resistance in MM in vivo and in vitro.

\section{Discussion}

Acquired drug resistance can be the result of the activation of an alternative compensatory signaling pathway [21], mutations or quantitative alterations that arise during therapy, or various adaptive responses. In this study, we established two BTZ-resistant cell lines by increasing the concentration of BTZ in a step-wise manner. DCZ3301 inhibited cell proliferation in a dose- and time-dependent manner. The flow cytometric results confirmed that DCZ3301-mediated pro-apoptotic effects were specific to the BTZ-resistant cells, since no significant apoptosis was detected in PBMCs treated with up 


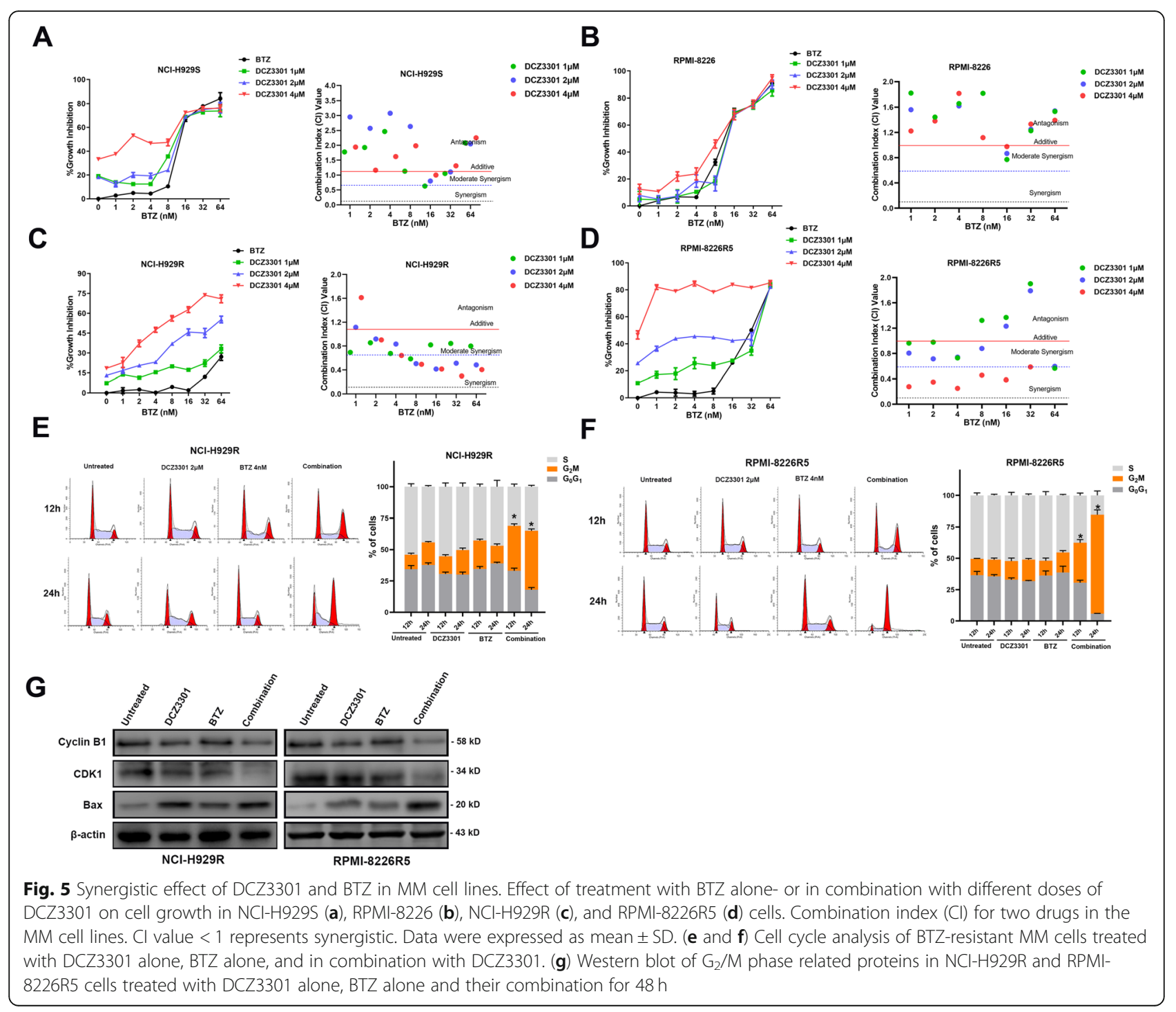

to $30 \mu \mathrm{M}$ DCZ3301. Both the $\mathrm{G}_{2}$ and $\mathrm{M}$ phase belong to the late stage of mitosis, and cells in these phases have the same DNA content. However, one of the most remarkable differences between the $G_{2}$ and $M$ phase is the chromatin condensation in the $G_{2}$ phase and chromosome formation in the $\mathrm{M}$ phase. The phosphorylation of Histone H3 Ser 10 is correlated with the progression of chromatin condensation [18, 24]. We found that after DCZ3301 treatment the phosphorylation of Histone H3 was significantly upregulated. This indicated that DCZ3301 inhibited BTZ-resistant cells in the $M$ phase and not the $G_{2}$ phase.

Next, we investigated the influence of DCZ3301 on the expression of $\mathrm{G}_{2} / \mathrm{M}$ checkpoint proteins. The checkpoint pathways involved in DNA damage or errors are phylogenetically conserved according to the previous report. The function of active checkpoints is delaying cell cycle progression to facilitate DNA repair [21]. CHK1 and CHK2 are major effectors of cell cycle regulation in these checkpoint proteins [25, 26]. During DNA damage, the key regulators in the checkpoint pathways, ATM and ATR kinases, are activated by phosphorylation that in turn phosphorylates H2A.X via the checkpoint kinases CHK1 or CHK2 to induce cell cycle arrest [12]. During the $G_{2}$ phase, CHK1 phosphorylates and suppresses $\mathrm{Cdc} 25-\mathrm{A},-\mathrm{B}$, and $-\mathrm{C}$, thereby preventing cyclin $\mathrm{B} 1 / \mathrm{cdk} 1$ activation, eventually leading to $G_{2}$ arrest $[27,28]$. Thus, the $G_{2}$ checkpoint is the last opportunity to halt the cycle and repair the DNA damage in cells that have escaped the $G_{1}$ and $S$ phase checkpoints.

Based on this information, we investigated whether DCZ3301 activated any of the upstream DNA damage signaling pathways. The comet assay and IF results showed that DCZ3301 aggravated DNA fragmentation. Also, the expression of phosphorylated CHK1 was upregulated. The protein $\gamma$-H2A.X Ser 139 is regarded as a 


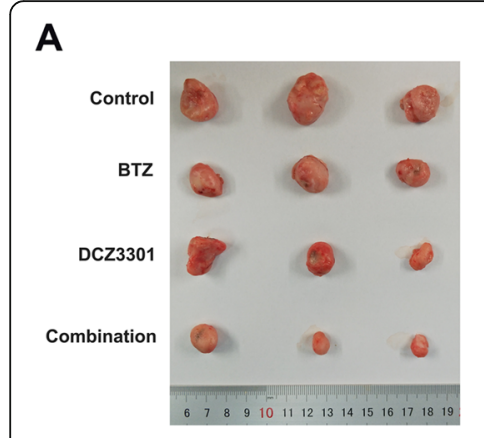

B
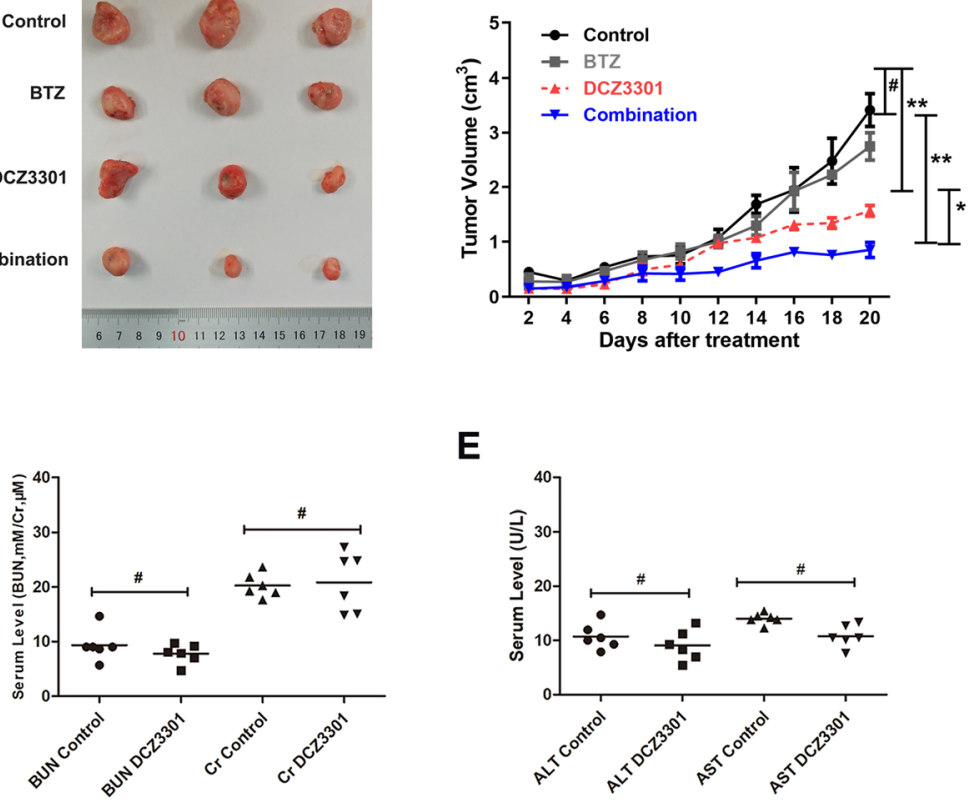

E

B

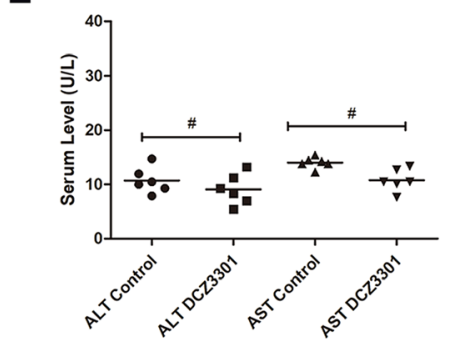

C

$\mathbf{F}$

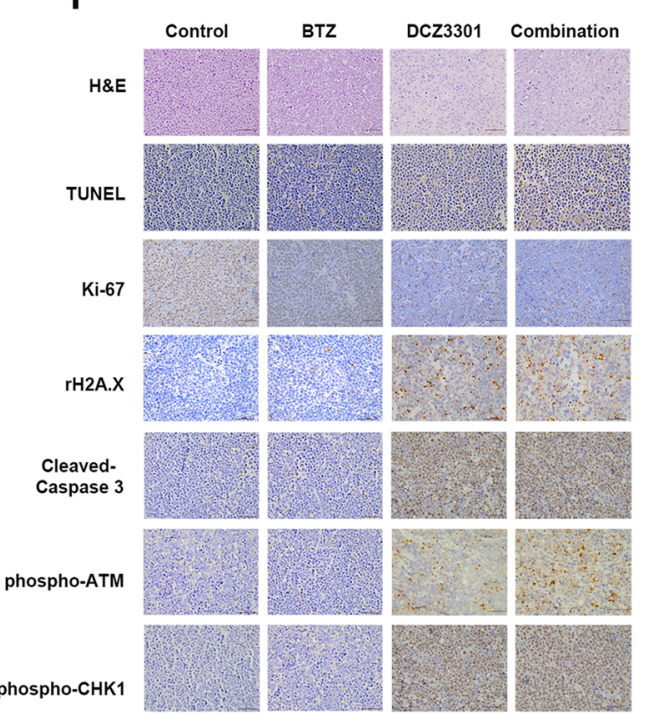

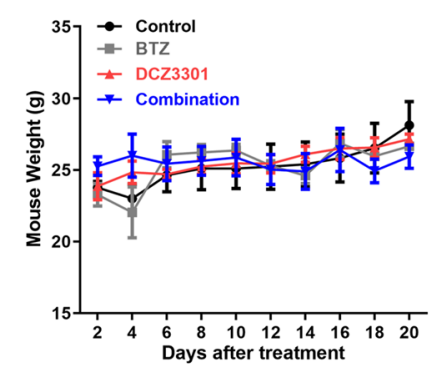

G

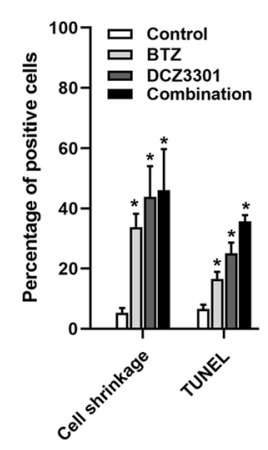

H

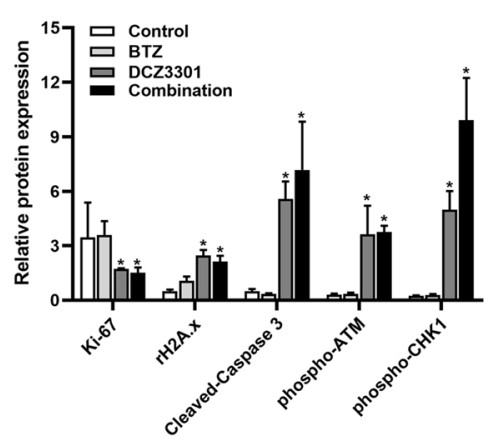

Fig. 6 Synergistic effect of DCZ3301 and BTZ against BTZ-resistant MM in vivo. (a) Gross appearance of tumors on day 20. (b) Tumor growth curves of 20 days treatment. (c) Growth curve of mouse weight ( $n=3$ for each group). (d) and (e) Serum levels of ALT, AST, Cr and BUN ( $n=6$ for each group). ${ }^{*} p<0.05, \# p>0.05$ Data were represented as mean $\pm \mathrm{SD}$. (f) H\&E staining of tumor sections for tumor histology after treatment. TUNEL, Ki-67, Y-H2A.X, cleaved caspase-3, phospho-ATM and phospho-CHK1 were stained immunohistochemically in tumor sections. (g) The percentage of cell shrinkage and TUNEL-positive cells in tumor sections. (h) The relative protein expressions of Ki-67, $\mathrm{Y}$-H2A.X, cleaved caspase-3, phospho-ATM and phospho-CHK1 quantified by Image Pro-plus in tumor sections

surrogate marker for DNA double-strand breaks [19, 29]. Activation of the DNA damage response includes the formation of DNA damage foci containing activated $\gamma$ H2A.X. Therefore, we examined the expression of $\gamma$ H2A.X and formation of $\gamma$-H2A.X foci using western blot and IF. DCZ3301 treatment upregulated $\gamma$-H2A.X expression and promoted the formation of $\gamma$-H2A.X foci. Further, DCZ3301 upregulated the phosphorylation of ATR, ATM, and their downstream proteins CHK1, and these effects could be blocked by KU55933, an ATM specific inhibitor. Collectively, the results confirmed that DCZ3301 induced DNA damage in BTZ-resistant MM cells.

We contemplated why DCZ3301-mediated DNA damage blocked BTZ-resistant MM cells in the M phase, and not the $G_{2}$ phase. The CyclinB1-CDK1 complex plays a regulatory role during the $\mathrm{G}_{2} / \mathrm{M}$ phase [30]. During DNA damage, CHK1 and CHK2 kinases phosphorylate and inactivate $\mathrm{Cdc} 25 \mathrm{C}$ [31], which in turn activates CDK1 by dephosphorylating it. Therefore, the $G_{2}$ checkpoint is the last opportunity to halt the cycle and repair DNA damage in cells that have escaped the $G_{1}$ and $S$ phase checkpoints [32]. During the $G_{2}$ phase, HR is the predominant pathway responsible for DNA repair [33]. Our results showed that DCZ3301 treatment impaired HR activity without affecting NHEJ activity in treated cells, thereby leading to irreparable DNA damage. This was associated with the downregulation of Rad51 [34]. However, in our study BRCA1 and BRCA2 were 
overexpressed. This response may be part of a DNA repair mechanism that lead to an initial upregulation of BRCA1 and BRCA2 in response to DCZ3301-mediated DNA damage. However, subsequent repair might be suppressed for some unknown reason. When DNA damage is not detected or repaired by the end of the $G_{2}$ phase, it leads to the activation of the cyclin B1-CDK1 complex by Cdc25 phosphatase [35]. In our study, DCZ3301 treatment decreased the expression of cyclin B1, CDK1, and Cdc25C, whereas it increased the phosphorylation of Cdc25C. Interestingly, flow cytometry showed that BTZ-resistant cells were blocked in the M phase and not the $G_{2}$ phase, which indicated that these cells might have "slipped" in the $\mathrm{M}$ phase with damaged DNA. We observed Histone H3 phosphorylation, which indicated that chromatin was indeed condensed during the $M$ phase. The premature mitotic entry of defective cells before proper chromosome segregation leads to mitotic catastrophe and cell death upon entering mitosis [36]. Our IF results showed that DCZ3301 treatment led to a mitotic catastrophe and confirmed these speculations.

Mitotic catastrophe shares several biochemical hallmarks of apoptosis [37]. We observed caspase- dependent apoptosis induced by DCZ3301 in vitro and necrosis in xenotransplanted tumors in vivo. Significantly, unlike normal cells, most cancer cells have aberrant cell cycle checkpoints, especially $G_{2}$ phase checkpoint, and are prone to mitotic catastrophe [21]. This explains the specificity of DCZ3301 in inducing the mitotic catastrophe in cancer cells but not in PBMCs. BTZ is reported to induce mitotic catastrophe through the ubiquitin-proteasome system in B-cell lymphoma cells [38]. However, BTZ resistance can arise through the therapy-induced selection of a minor resistant cell subpopulation present in MM [21]. Based on our results, we propose that DCZ3301 acts synergistically with BTZ and reprograms BTZ-resistant cells to restore their sensitivity through complementary mechanisms.

\section{Conclusions}

In conclusion, we identified the mechanism of action of DCZ3301, a novel compound previously reported by us, that can enhance the sensitivity of BTZ in resistant MM. It activates DNA damage, inhibits DNA repair, and induces mitotic catastrophe through the ATM-ATR/CHK/ Cdc25C pathway (Fig. 7) in BTZ-resistant cells. In addition, DCZ3301 acts synergistically with BTZ in vitro

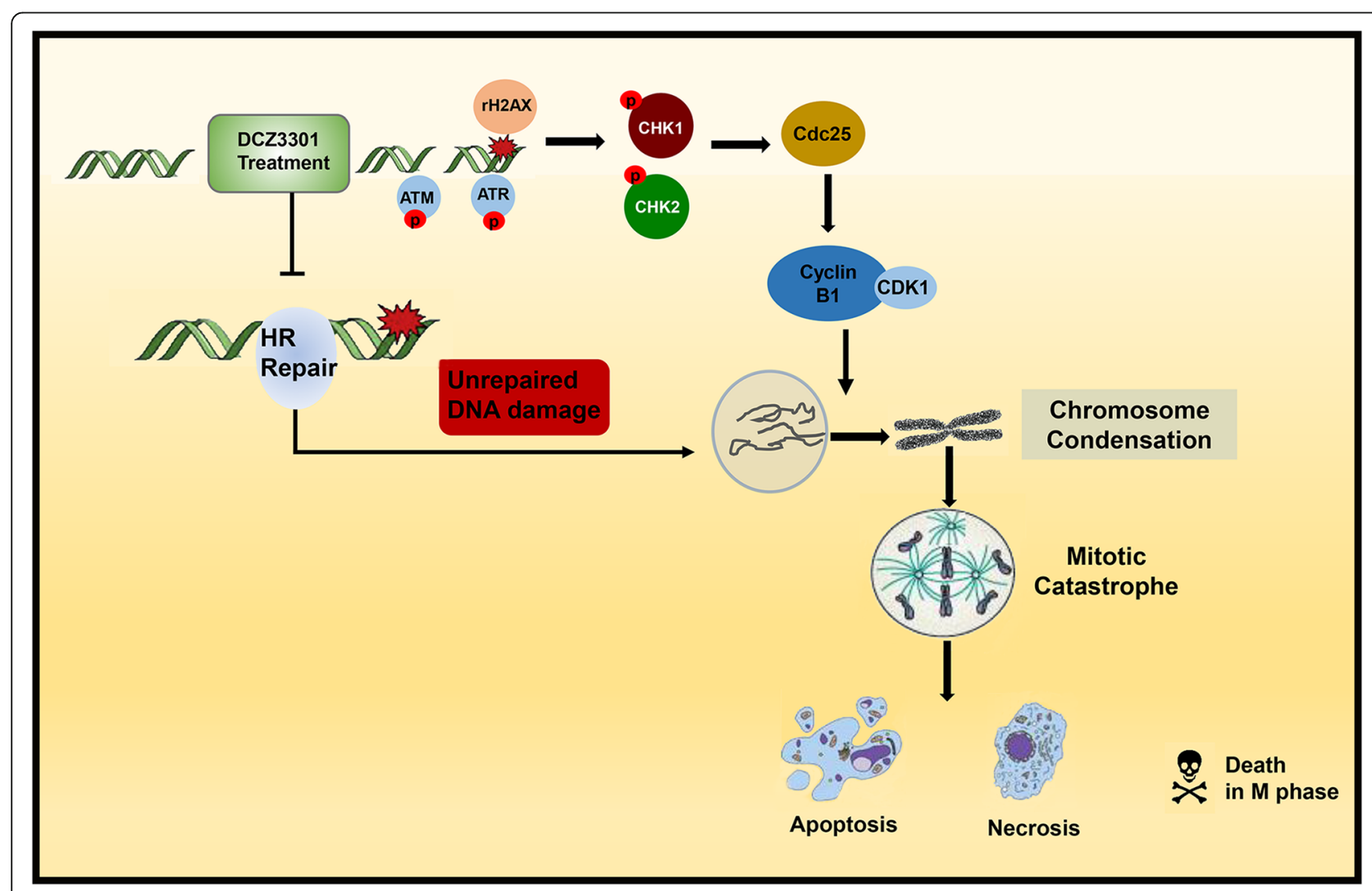

Fig. 7 Diagram illustrating the mechanism of DCZ3301 effect on DNA damage and $G_{2} / M$ checkpoint regulation 
and in vivo. It enhances the BTZ-induced $G_{2} / M$ phase arrest and leads cells into mitotic catastrophe through complementary mechanisms. Collectively, these findings suggest that DCZ3301 may hold promise for BTZresistant MM therapy and may provide an effective strategy for BTZ resistance prevention and treatment.

\section{Supplementary information}

Supplementary information accompanies this paper at https://doi.org/10. 1186/s13046-020-01597-9.

Additional file 1: Supplementary Table 1-8. Detailed concentrations of DCZ3301 and BTZ used in the synergistic experiments.

Supplementary Figure 1. DCZ3301 was synergistic with the histone deacetylase (HDAC) inhibitor panobinostat in NCl-H929R and RPMI8226R5 cells

\section{Abbreviations}

ATM: Ataxia telangiectasia mutated; BTZ: Bortezomib; CHK1: Checkpoint kinase 1; CHK2: Checkpoint kinase 2; DDR: DNA damage response; DLBCL: Diffuse large B-cell lymphoma; DSBs: Double strand breaks; FDA: Food and Drug Administration; H\&E: Hematoxylin \& eosin; MM: Multiple myeloma; NHEJ: Non-homologous end joining; PARP: Poly (ADP)-ribose polymerase; SD: Standard deviation

\section{Acknowledgements}

We thank Mengyu Xi (Institute of Materia Medica, Chinese Academy of Sciences, Shanghai) for her dedicated works in synthetizing DCZ3301. We thank Nan Huang (Department of Laboratory Medicine, Shanghai Tenth People's Hospital of Tongji University) for kindly providing NHEJ and HR report plasmids. We also express our gratitude to Ni Zhen (Department of Laboratory Medicine, Shanghai Tenth People's Hospital of Tongji University) for guiding us carrying out the DNA repair related experiments.

\section{Authors' contributions}

Conceptualization and design: Shi J. and Zhu W Development of methodology: Hu L., Li B., Chen G., Song D., Xu Z., Gao L., Xi M., Li L., Zhang $\mathrm{H}$ and Feng Q. Acquisition of data (provided animals acquired and managed patients, provide facilities, etc.): Hu L., Li B., Chen G., Wang Y., Lu K., Lu Y., Bu W Wang $\mathrm{H}$. and Wu X. Analysis and interpretation of data (e.g., statistical analysis, software, visualization): Hu L., Li B., Song D., Lu K., Bu W and Zhang H. Writing and review of the manuscript: Hu L., Li B., Chen G., Shi J., Zhu W and Wu X. Administrative, technical, or material support (i.e., reporting or organizing data, constructing database): Hu L., Li B., Chen G., Lu K., Zhang H., Bu W., Wang H., Shi J., Zhu W and Wu X. The authors read and approved the final manuscript.

\section{Funding}

This work was supported by the National Natural Science Foundation of China [Grant numbers: 81529001, 81670194, 81600174 and 81870158]; Natural Science Foundation of Shanghai, China [Grant number: 19ZR1467800]; and National Science \& Technology Major Project "Key New Drug Creation and Manufacturing Program", China [Grant number: 2018ZX09711002].

\section{Availability of data and materials}

The datasets supporting the conclusions of this article are included in this published article (and its supplementary information files).

\section{Ethics approval and consent to participate}

This study was approved by the institutional review board of the Shanghai Tenth People's Hospital, Tongji University.

\section{Consent for publication}

Not applicable.

\section{Competing interests}

The authors declare no conflict of interest.

\section{Author details}

'Department of Hematology, Shanghai Tenth People's Hospital, Tongji University School of Medicine, 301 Yanchang Road, Shanghai 200072, China. ${ }^{2}$ CAS Key Laboratory of Receptor Research, Drug Discovery and Design Center, Shanghai Institute of Materia Medica, Chinese Academy of Sciences, 555 Zuchongzhi Road, Shanghai 201203, China. ${ }^{3}$ Tongji University Cancer Center, Tongji University, Shanghai 200092, China.

Received: 30 November 2019 Accepted: 18 May 2020

Published online: 09 June 2020

\section{References}

1. Mujtaba T, Dou QP. Advances in the understanding of mechanisms and therapeutic use of bortezomib. Discov Med. 2011;12(67):471-80.

2. Twombly R. First proteasome inhibitor approved for multiple myeloma. J Natl Cancer Inst. 2003;95(12):845.

3. Murray MY, Auger MJ, Bowles KM. Overcoming bortezomib resistance in multiple myeloma. Biochem Soc T. 2014:42(4):804-8.

4. Ludwig H, Beksac M, Bladé J, Boccadoro M, Cavenagh J, Cavo M, Dimopoulos M, Drach J, Einsele H, Facon T, et al. Current multiple myeloma treatment strategies with novel agents: a European perspective. Oncologist. 2010;15(1):6-25.

5. Alimbetov D, Askarova S, Umbayev B, Davis T, Kipling D. Pharmacological targeting of cell cycle, apoptotic and cell adhesion signaling pathways implicated in Chemoresistance of Cancer cells. Int J Mol Sci. 2018;19(6):1690.

6. Johnsen HE, Bøgsted M, Schmitz A, Bødker JS, El-Galaly TC, Johansen P, Valent P, Zojer N, Van Valckenborgh E, Vanderkerken K, et al. The myeloma stem cell concept, revisited: from phenomenology to operational terms. Haematologica. 2016;101(12):1451-9.

7. Gao M, Kong Y, Yang G, Gao L, Shi J. Multiple myeloma cancer stem cells. Oncotarget. 2016;7(23):35466-77.

8. Bao S, Wu Q, McLendon RE, Hao Y, Shi Q, Hjelmeland AB, Dewhirst MW Bigner DD, Rich JN. Glioma stem cells promote radioresistance by preferential activation of the DNA damage response. Nature. 2006; 444(7120):756-60.

9. Matt S, Hofmann TG. The DNA damage-induced cell death response: a roadmap to kill cancer cells. Cell Mol Life Sci. 2016;73(15):2829-50.

10. Chou WC, Hu LY, Hsiung CN, Shen CY. Initiation of the ATM-Chk2 DNA damage response through the base excision repair pathway. Carcinogenesis. 2015;36(8):832-40.

11. Kabeche L, Nguyen HD, Buisson R, Zou L. A mitosis-specific and R loopdriven ATR pathway promotes faithful chromosome segregation. Science (New York, N.Y.). 2018;359(6371):108-14.

12. Smith J, Tho LM, Xu N, Gillespie DA. The ATM-Chk2 and ATR-Chk1 pathways in DNA damage signaling and cancer. Adv Cancer Res. 2010;108:73-112.

13. Sun X, Li B, Xie B, Xu Z, Chang G, Tao Y, Zhang Y, Chang S, Wang Y, Yu D, et al. DCZ3301, a novel cytotoxic agent, inhibits proliferation in diffuse large B-cell lymphoma via the STAT3 pathway. Cell Death Dis. 2017;8(10):e3111.

14. Xiao W, Li B, Sun X, Yu D, Xie Y, Wu H, Chang S, Zhou Y, Wang H, Lan X, et al. DCZ3301, a novel aryl-guanidino inhibitor, induces cell apoptosis and cell cycle arrest via suppressing the PI3K/AKT pathway in T-cell leukemia/ lymphoma. Acta Bioch Bioph Sin. 2018;50(7):643-50.

15. Gao M, Li B, Sun X, Zhou Y, Wang Y, Tompkins VS, Xu Z, Indima N, Wang H, Xiao W, et al. Preclinical activity of DCZ3301, a novel aryl-guanidino compound in the therapy of multiple myeloma. Theranostics. 2017;7(15): 3690-9.

16. Zhen N, Jin L, Ma J, Zhu J, Gu S, Wang J, Pan Q, Ni X, Xu M. Ginsenoside Rg1 impairs homologous recombination repair by targeting CtBPinteracting protein and sensitizes hepatoblastoma cells to DNA damage. Anti-Cancer Drugs. 2018;1(3):1.

17. Zhen N, Gu S, Ma J, Zhu J, Yin M, Xu M, Wang J, Huang N, Cui Z, Bian Z, et al. CircHMGCS1 promotes Hepatoblastoma cell proliferation by regulating the IGF signaling pathway and Glutaminolysis. Theranostics. 2019;9(3):900-19.

18. Vignon C, Debeissat C, Georget MT, Bouscary D, Gyan E, Rosset P, Herault O. Flow cytometric quantification of all phases of the cell cycle and apoptosis in a two-color fluorescence plot. PLoS One. 2013;8(7):e68425.

19. Walters DK, Wu X, Tschumper RC, Arendt BK, Huddleston PM, Henderson KJ Dispenzieri A, Jelinek DF. Evidence for ongoing DNA damage in multiple myeloma cells as revealed by constitutive phosphorylation of $\mathrm{H} 2 \mathrm{AX}$ Leukemia. 2011;25(8):1344-53. 
20. Robak P, Drozdz I, Szemraj J, Robak T. Drug resistance in multiple myeloma. Cancer Treat Rev. 2018;70:199-208.

21. Denisenko TV, Sorokina IV, Gogvadze V, Zhivotovsky B. Mitotic catastrophe and cancer drug resistance: a link that must to be broken. Drug Resist Update. 2016;24:1-12.

22. Chou TC. Drug combination studies and their synergy quantification using the Chou-Talalay method. Cancer Res. 2010;70(2):440-6.

23. Chou TC. Theoretical basis, experimental design, and computerized simulation of synergism and antagonism in drug combination studies Pharmacol Rev. 2006;58(3):621-81.

24. Castellano-Pozo M, Santos-Pereira JM, Rondón AG, Barroso S, Andújar E, Pérez-Alegre M, García-Muse T, Aguilera A. R loops are linked to histone H3 S10 phosphorylation and chromatin condensation. Mol Cell. 2013;52(4):583-90.

25. McGowan CH. Checking in on Cds1 (Chk2): a checkpoint kinase and tumor suppressor. Bioessays. 2002;24(6):502-11.

26. Bartek J, Lukas J. DNA repair: damage alert. Nature. 2003;421(6922):486-8.

27. Bucher N, Britten CD. G2 checkpoint abrogation and checkpoint kinase-1 targeting in the treatment of cancer. Brit J Cancer. 2008;98(3):523-8.

28. Boutros $R$, Dozier C, Ducommun B. The when and wheres of CDC25 phosphatases. Curr Opin Cell Biol. 2006;18(2):185-91.

29. Xiao A, Li H, Shechter D, Ahn SH, Fabrizio LA, Erdjument-Bromage H, IshibeMurakami S, Wang B, Tempst P, Hofmann K, et al. WSTF regulates the H2A.X DNA damage response via a novel tyrosine kinase activity. Nature. 2009; 457(7225):57-62.

30. Afonso O, Castellani CM, Cheeseman LP, Ferreira JG, Orr B, Ferreira LT, Chambers JJ, Morais-de-Sa E, Maresca TJ, Maiato H. Spatiotemporal control of mitotic exit during anaphase by an Aurora B-Cdk1 crosstalk. Elife. 2019;8: e47646.

31. Singh RP, Dhanalakshmi S, Agarwal R. Phytochemicals as cell cycle modulators--a less toxic approach in halting human cancers. Cell Cycle. 2002;1(3):156-61.

32. Poehlmann A, Habold C, Walluscheck D, Reissig K, Bajbouj K, Ullrich O, Hartig R, Gali-Muhtasib H, Diestel A, Roessner A, et al. Cutting edge: Chk1 directs senescence and mitotic catastrophe in recovery from $\mathrm{G} 2$ checkpoint arrest. J Cell Mol Med. 2011;15(7):1528-41.

33. Meena SLPD. Regulation of DNA double-strand break repair pathway choice. Cell Res. 2008:18(1):134-47.

34. Pires E, Sung P, Wiese C. Role of RAD51AP1 in homologous recombination DNA repair and carcinogenesis. DNA Repair. 2017;59:76-81.

35. On KF, Chen Y, Tang Ma H, Chow JPH, Poon RYC. Determinants of mitotic catastrophe on abrogation of the G2 DNA damage checkpoint by UCN-01. Mol Cancer Ther. 2011;10(5):784-94

36. Vitale I, Galluzzi L, Castedo M, Kroemer G. Mitotic catastrophe: a mechanism for avoiding genomic instability. Nat Rev Mol Cell Biol. 2011;12(6):385-92.

37. Castedo M, Perfettini JL, Roumier T, Andreau K, Medema R, Kroemer G. Cell death by mitotic catastrophe: a molecular definition. Oncogene. 2004; 23(16):2825-37.

38. Gu J, Kaufman GP, Mavis C, CZuczman MS, Hernandez-Ilizaliturri FJ. Mitotic catastrophe and cell cycle arrest are alternative cell death pathways executed by bortezomib in rituximab resistant B-cell lymphoma cells. Oncotarget. 2017;8(8):12741-53.

\section{Publisher's Note}

Springer Nature remains neutral with regard to jurisdictional claims in published maps and institutional affiliations.

Ready to submit your research? Choose BMC and benefit from:

- fast, convenient online submission

- thorough peer review by experienced researchers in your field

- rapid publication on acceptance

- support for research data, including large and complex data types

- gold Open Access which fosters wider collaboration and increased citations

- maximum visibility for your research: over $100 \mathrm{M}$ website views per year

At $\mathrm{BMC}$, research is always in progress.

Learn more biomedcentral.com/submissions 